\title{
Enhancements to a Propulsion Demonstrator
}

\section{Dr. Rafic Bachnak, Texas A\&M International University}

Dr. Bachnak is professor and chair of the Department of Engineering, Mathematics, and Physics at Texas A\&M International University (TAMIU). He received his B.S., M.S., and Ph.D. degrees in Electrical Engineering from Ohio University in 1983, 1984, and 1989, respectively. Prior to joining TAMIU in 2007, Dr. Bachnak was on the faculty of Texas A\&M-Corpus Christi, Northwestern State University, and Franklin University. His experience includes several fellowships with NASA and the US Navy Laboratories and employment with Koch Industries. Dr. Bachnak is a registered Professional Engineer in the State of Texas, a senior member of IEEE and ISA, and a member of ASEE. During the 2009-2010 academic year, he was a Fulbright Scholar at Notre Dame University, Lebanon.

\section{Miss Sofía Carolina Maldonado, Texas A\&M International University}

Sofía Carolina Maldonado is a graduate student at Texas A\&M International University (TAMIU), currently completing a M.S. in Information Systems. She obtained her B.S. degree in Systems Engineering from the same University in Fall 2011. Sofía was a Distinguished Student Scholar and Student respondent at the Fall 2011 Commencement Ceremony. Throughout her TAMIU education, she has been a member of the Phi Kappa Phi Honor Society and Vice-President and Treasurer of the Society of Engineering at TAMIU. In addition, Sofía was a Research Assistant for the project "Topography of an Object: Detection and Display (Software and Hardware)" and was team leader of the Engineering Senior Project Design entitled "New Classroom Propulsion Demonstrator."

\section{Dr. Fernando Garcia Gonzalez, Texas A\&M International University}

Dr. Fernando Gonzalez is an Assistant Professor in the Engineering Math and Physics Department at Texas A\&M International University in Laredo, Texas. He is currently involved in implementing a new undergraduate Systems Engineering degree program which includes selecting the curriculum for the program, designing new labs, selecting new equipment for these labs, hiring new faculty, work towards ABET accreditation, and student recruitment. Dr. Gonzalez graduated from the University of Illinois in 1997 with a Ph.D. in Electrical Engineering. He received his Master's degree in Electrical Engineering and his Bachelor's degree in Computer Science from Florida International University in 1992 and 1989. Dr. Gonzalez research interest includes the intelligent control of large scale autonomous systems, autonomous vehicles, discrete-event modeling and simulation and human signature verification. After his graduation he spent nine years as a faculty member in the Electrical and Computer Engineering Department of the University of Central Florida. Before joining Texas A\&M International University he was a Researcher at Los Alamos National Laboratory in Los Alamos, New Mexico. 


\title{
Enhancements to a Propulsion Demonstrator
}

\begin{abstract}
This paper presents enhancements to a propulsion demonstrator that illustrates how a rocket works. The operation of the original system is manual and collection and display of useful data is not possible. The updated system consists of the following major components: (1) a computercontrolled ignition mechanism; (2) a programmable valve that allows control of oxygen flow during the ignition phase and throughout the demonstration process; (3) temperature and pressure sensors inside the rocket chamber to monitor the behavior of the system and allow computation of resulting thrust; and (4) a data acquisition board for interfacing the various components. The system can be assembled in five minutes and is fully controlled by software via push buttons in a LabVIEW ${ }^{\mathrm{TM}}$ programming environment. This paper documents the major system components and discusses test results.
\end{abstract}

\section{Introduction}

Science, technology, engineering, and mathematics (STEM) are vital to American competitiveness, yet relatively few students obtain a STEM bachelor's degree. While the number of degrees awarded in the STEM fields increased modestly from 2003 to 2007, only 15.6 percent of bachelor's degrees were awarded in these fields, and the overall share of degrees awarded in STEM fields actually shrank during this period. Meanwhile, China awarded nearly half of its first university degrees in STEM fields (46.7 percent); South Korea awarded 37.8 percent; and Germany awarded 28.1 percent $^{1}$.

Three overarching priorities for STEM education are necessary for laying a new foundation for America's future prosperity: increasing STEM literacy so all students can think critically in STEM subjects; improving the quality of math and science teaching so American students are no longer outperformed by those in other nations; and expanding STEM education and career opportunities for underrepresented groups, including women and minorities. In the knowledgebased economy of the 21 st Century, students will need to graduate from high school with a solid grounding in the STEM fields so they are prepared for postsecondary education and careers ${ }^{2}$. A successful STEM education creates critical thinkers, increases science literacy, and enables the next generation of innovators. Innovation leads to new products and processes that sustain the economy. This innovation and science literacy depends on a solid knowledge base in the STEM areas. It is clear that most jobs of the future will require a basic understanding of math and science - 10-year employment projections by the U.S. Department of Labor show that of the 20 fastest growing occupations projected for 2014, 15 of them require significant mathematics or science preparation $^{3}$.

The classroom propulsion demonstrator was developed at Stennis Space Center to demonstrate how a rocket works at scale to high school and university students. The main purpose of this apparatus is to raise awareness of STEM education. The original system consists of an oxygen tank connected to an assembly base through a gas line. Before firing the device, an igniter is connected to a 12 Volt battery and the gas lines are manually opened. An acrylic cylinder 
chamber inside the assembly base starts filling up with oxygen, which spreads inside the chamber. In addition, steel wool is wrapped around the igniter and placed at the entrance of the acrylic cylinder to help initiate the fire inside the apparatus. Sparks are generated by the igniter and oxygen causes the fire to expand. This system is not easy to assemble and the whole operation is manual.

This paper presents improvements to the original system including an automated ignition mechanism, control and monitoring of oxygen flow, temperature and pressure measurements, and thrust calculations.

\section{Overall System Design and Operation}

The new propulsion demonstrator is operated and controlled through a computer via a LabVIEW ${ }^{\mathrm{TM}}$ user interface. When started, a signal is transmitted to the ignition mechanism and the mass flow controller (valve). Oxygen is used to ignite the system with the help of steel wool. The program allows monitoring and control of oxygen flow. The system also has a safety mechanism that immediately shuts off the supply line in case of an emergency or if the sensor detects a failure. Thrust calculations are performed in real-time using temperature and pressure measurements. Figure 1 shows a block diagram that illustrates the design and operation of the new propulsion demonstrator.

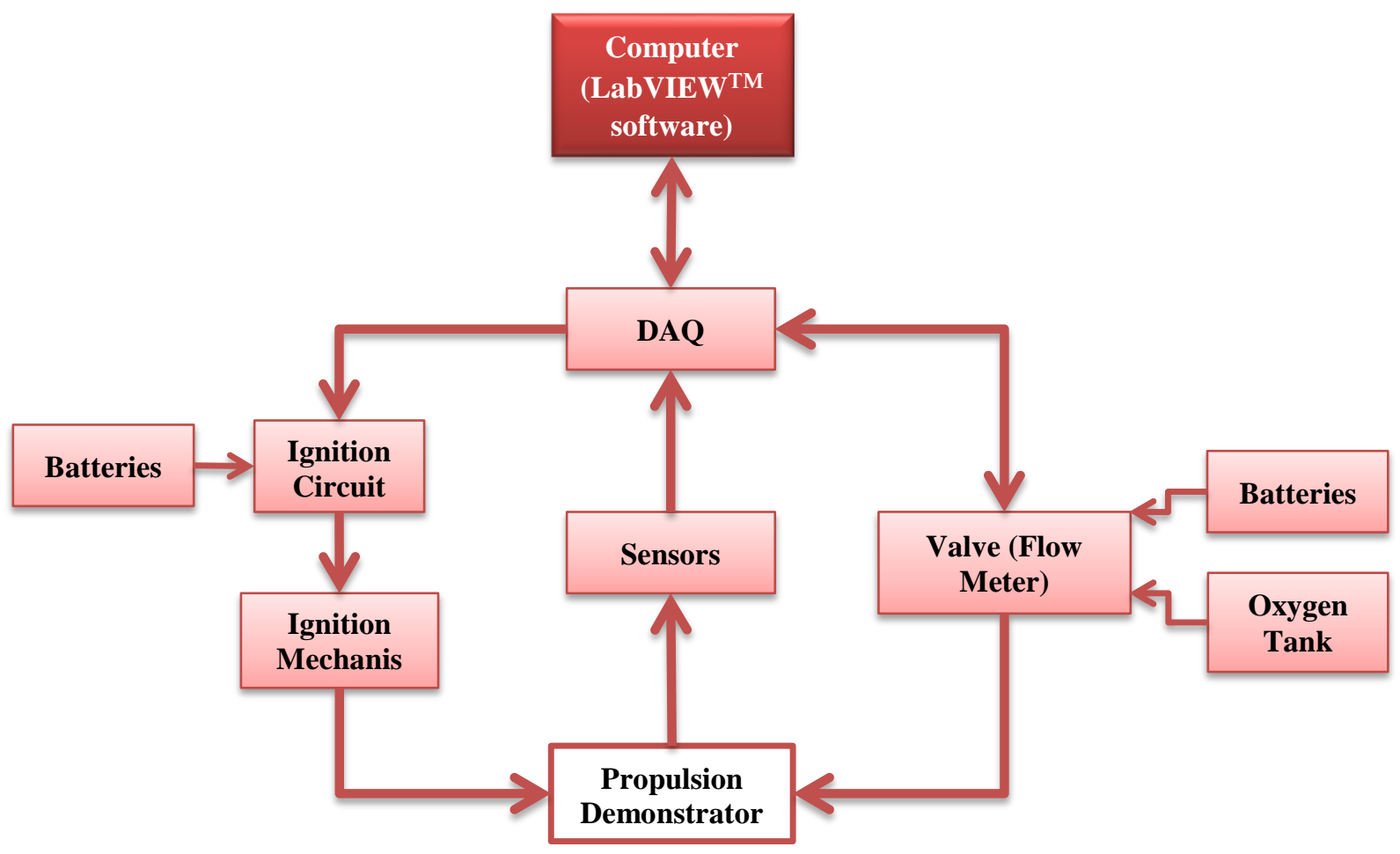

Figure 1. Enhanced Propulsion Demonstrator Block Diagram

The shape of the original system was modified to make it resemble an actual rocket. The barrel (acrylic cylinder) of the new system is one inch longer than the original one making the process last longer. In addition, the rear end (injector) of the apparatus was modified making it easier to 
connect to the oxygen hose. This change also allows for quick refueling. The original four posts connecting both ends of the device was changed to two standoffs, one on each side making it easier to remove without disassembling the whole unit. The new device also includes pressure and temperature sensors, mounted on the top and bottom, respectively. Figure 2 shows sketches of the design.
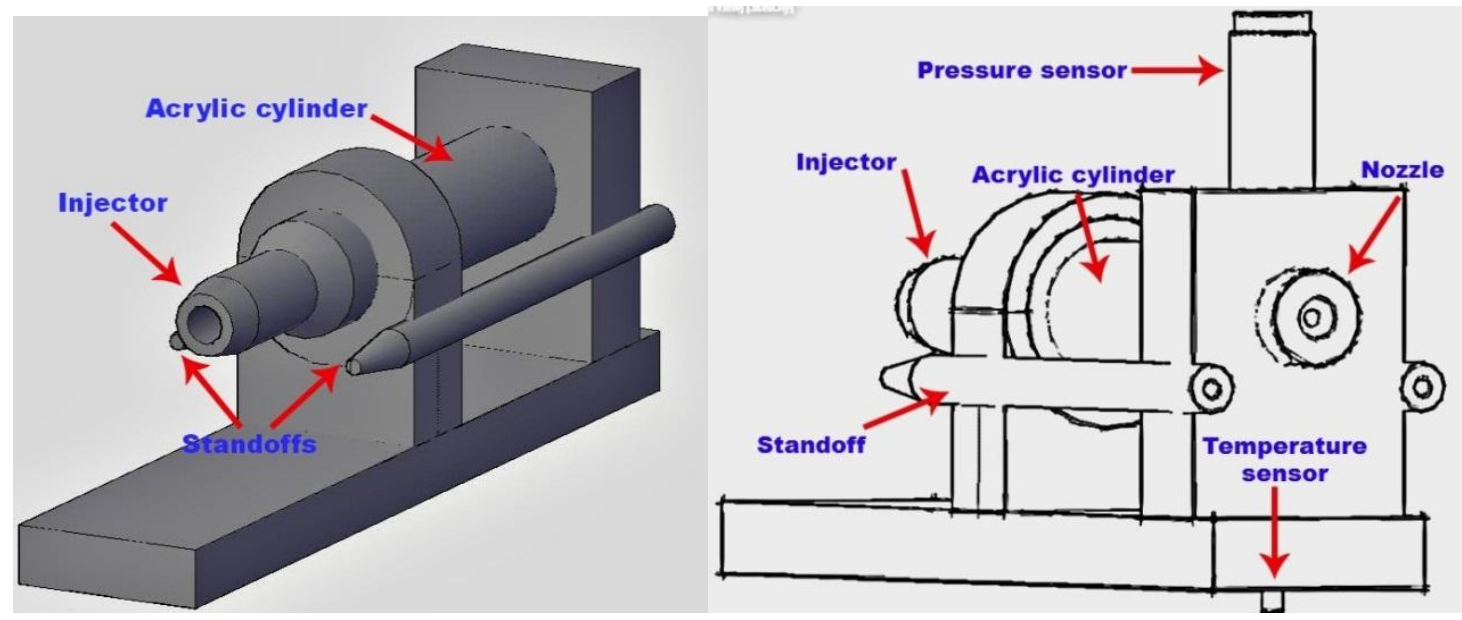

Figure 2. Enhanced Propulsion Demonstrator Design

\section{Hardware Components and Testing}

The following paragraphs describe the major system components and their functionality.

\section{Ignition Circuit:}

The ignition circuit is shown in Figure 3. A Single Pole Double Throw (SPDT) Relay is used to energize the system via the Data Acquisition board DAQ (NI USB-6211). The Op-Amp voltage follower isolates the DAQ from the rest of the circuit and provides the required current to operate the transistor ${ }^{4}$. The DAQ closes the relay and activates the ignition using the transistor as an amplifier. Once the transistor receives 5 volts on the base, it activates. The coil then energizes closing the internal switch connecting in the relay. The ignition mechanism was successfully tested before integration with the rest of the components.

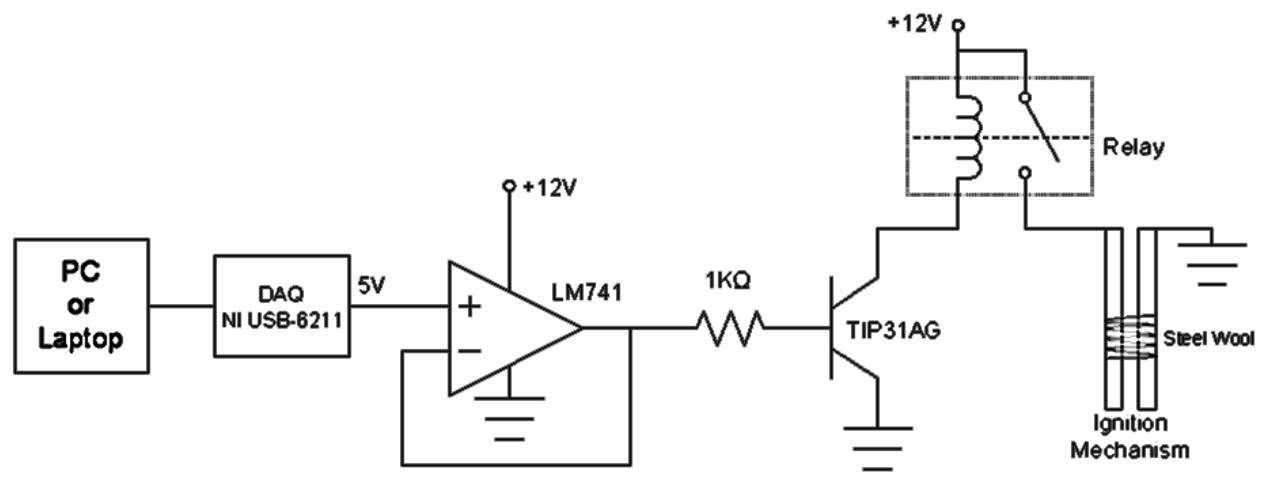

Figure 3. Ignition Circuit 


\section{Temperature Sensor:}

Initially an Industrial Resistance Temperature Detector (RTD) Probe was used but the maximum temperature of the device is not sufficiently hot for this application. Test results of the RTD are shown in the following table. The readings in Ohms were converted to degrees using the manufacturer's Temperature vs. Resistance Table ${ }^{6}$.

\begin{tabular}{|cc|}
\hline Ohms & Temperature in Celsius \\
\hline $\mathbf{1 1 9}$ ohms & $49 \mathrm{C}$ \\
\hline $\mathbf{1 1 0}$ ohms & $26 \mathrm{C}$ \\
\hline $\mathbf{1 0 0}$ ohms & $0 \mathrm{C}$ \\
\hline $\mathbf{9 8}$ ohms & $-5 \mathrm{C}$ \\
\hline
\end{tabular}

Testing the sensor at zero degrees was accomplished by placing it in ice. The sensor was placed in a freezer in the case of $-5^{\circ} \mathrm{C}$. The RTD sensor failed in an actual system test and is now being replaced by a thermocouple probe. The thermocouple has a maximum temperature rating of $650^{\circ} \mathrm{C}\left(1200^{\circ} \mathrm{F}\right)^{7}$ as opposed to $49^{\circ} \mathrm{C}$.

\section{Pressure Sensor:}

An OMEGA PX209 Series general purpose pressure transducer was used. This sensor was found to be reliable and suitable for this particular environment ${ }^{8}$. The Certificate of Calibration from Omega Engineering is as follows:

\begin{tabular}{|cc|}
\hline Voltage Output & Pressure Range \\
\hline 0 volts & 0 psia \\
\hline 5 volts & $250 \mathrm{psia}$ \\
\hline 10 volts & $500 \mathrm{psia}$ \\
\hline
\end{tabular}

The sensor was connected to the new device located in path of the air flow. A voltmeter was used to measure the voltage across the sensor and gave a reading between 5 to 8 volts when powered at $12 \mathrm{~V}$. After testing the system, the pressure sensor was slightly damaged due to the proximity of the sensor to the flame. To address this problem, the sensor was moved about 3 inches above the air chamber connected to an extension tube.

Valve/Mass Flow Controller:

A Brooks Model 5850E Mass Flow Controller ${ }^{9}$ was used to control the oxygen in the gas line and to read the airflow rate. The required voltage of -15 to 15 Volts DC led to the usage of 2 batteries and a power regulator. The valve performed opened as expected with satisfactory results.

\section{Data Acquisition Board (DAQ):}

The NI USB-6211 DAQ was used with the LabVIEW ${ }^{\text {TM }}$ software. This DAQ offers 16 analog inputs; $250 \mathrm{kS} / \mathrm{s}$ single-channel sampling rate; two analog outputs; four digital input lines; four 
digital output lines; four programmable input ranges $( \pm 0.2$ to $\pm 10 \mathrm{~V})$ per channel; digital triggering; and two counter/timers ${ }^{10}$. Figure 4 shows a table of the connections.
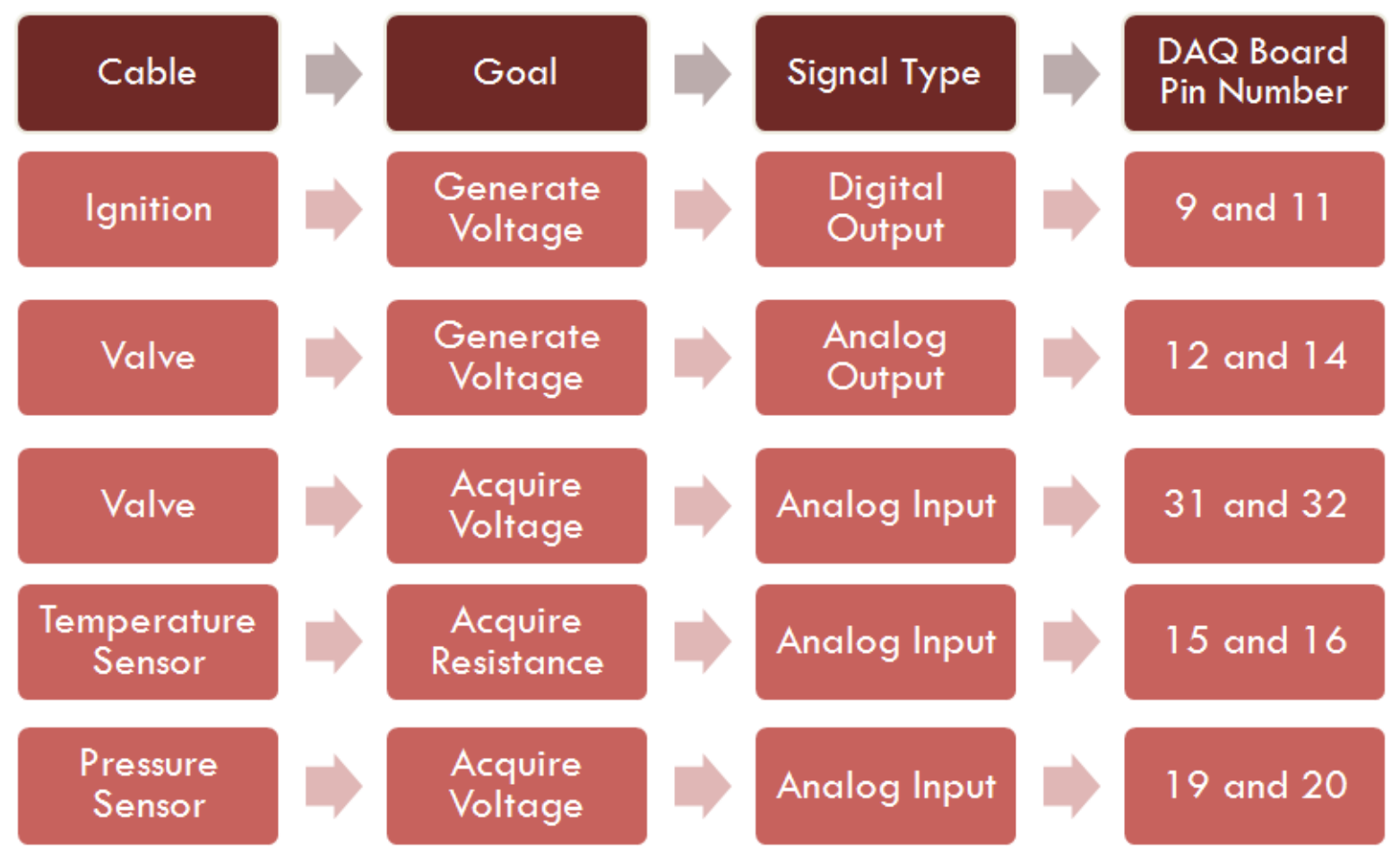

Figure 4. DAQ Integration

When testing the DAQ with the ignition mechanism, the SignalExpress icon in LabVIEWTM was employed to automatically read the DAQ Board and provide the necessary voltage to the ignition system. LabVIEW ${ }^{\mathrm{TM}}$ successfully turns the propulsion demonstrator's ignition system on and off. A second test was made in which the ignition system was turn on by simply pushing a single start button in the Front Panel of the LabVIEW ${ }^{\mathrm{TM}}$ program. The analog signal generation feature was used to provide the voltage needed to activate the ignition system.

\section{Software Development and Evaluation}

The complete system operation, including control and monitoring, was accomplished through a LabVIEW ${ }^{\mathrm{TM}}$ program. The following paragraphs provide additional details.

\section{User Interface:}

The LabVIEW ${ }^{\mathrm{TM}}$ front panel is shown in Figure 5. The user interface includes:

1. Mass Flow Rate Channels: Data Acquisition Board channel prompt.

2. Valve Flow Controller: Valve Flow Voltage Controller + Flow vs. Time Graph.

3. Pressure Sensor: Pressure Sensor Readings + Pressure Out vs. Time Graph.

4. Temperature Sensor: Temperature Sensor Readings + Temperature Out Graph.

5. Thrust Measurements: Thrust Measurements + Thrust vs. Time Graph. 
6. Close Valve Flow Controller Button: contains a START and emergency STOP button.

7. Delay Timers: gives time for the oxygen to reach the chamber before firing the system.

8. Thrust formula with indicators.

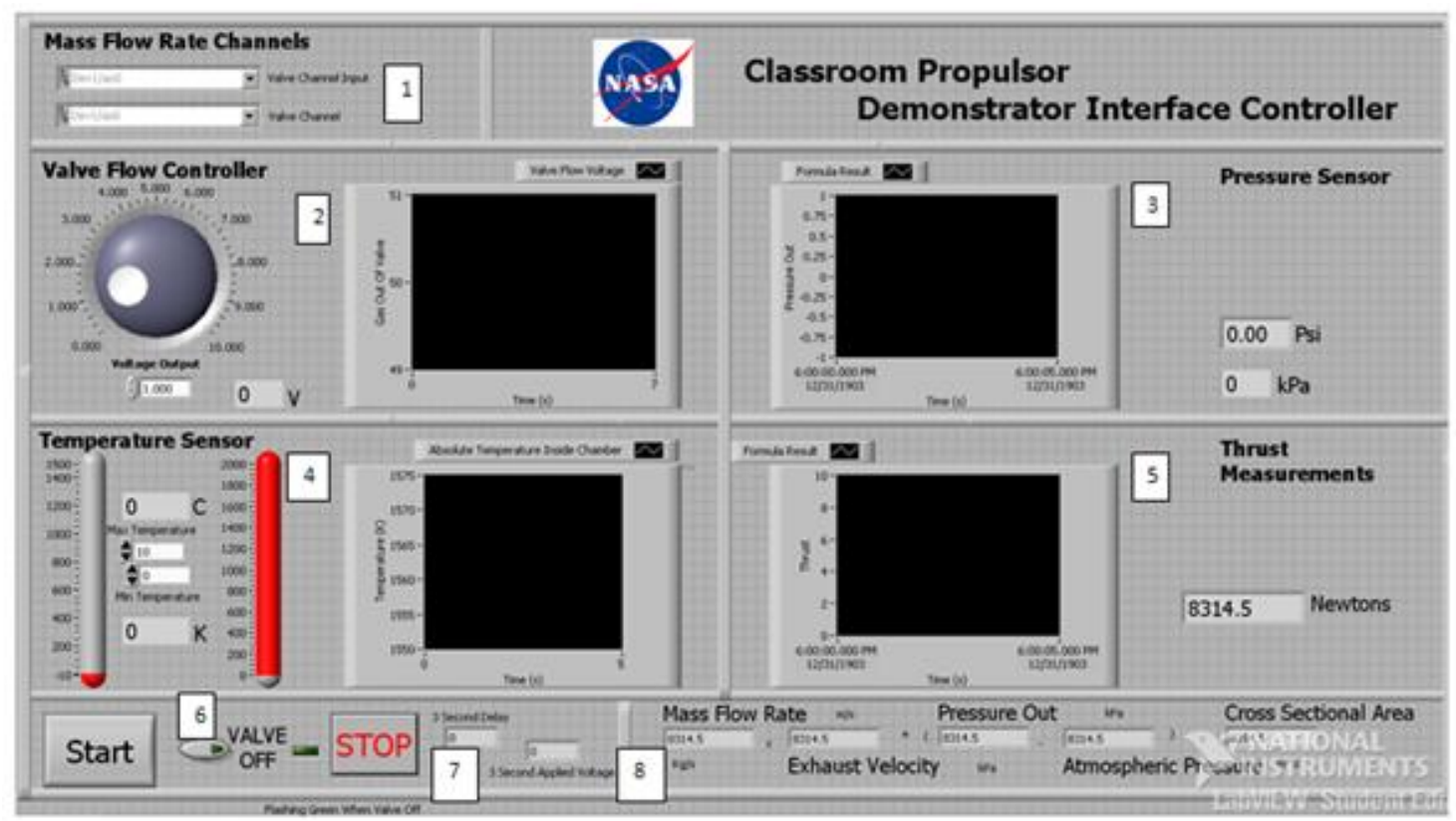

Figure 5. Front Panel of the User Interface

Thrust calculation:

The program computes the thrust using the following relationship:

(1) Thrust $=F=\dot{m} V_{e}+\left(p_{e}-p_{o}\right) A_{e}$

Where $\dot{m}=$ mass flow rate, $V_{e}=$ exit (exhaust) velocity, $p_{e}=$ exit pressure, $p_{o}=$ free stream pressure, and $A_{e}=$ area ratio from the throat to the exit ${ }^{11}$.

(2) $\dot{m}=d V A$

Where $d=$ density, $V=$ velocity, and $A=\operatorname{area}^{12}$.

(3) $V_{e}=\sqrt{\frac{T R}{M} * \frac{2 k}{k-1} *\left[1-\left(P_{e} / P\right)^{(k-1) / k}\right]}$

And

$T=$ absolute temperature of inlet gas,

$R=$ Universal Gas Law constant,

$M=$ gas molecular mass (molecular weight),

$k=c_{p} / c_{v}=$ isentropic expansion factor,

$c_{p}=$ specific heat of the gas at constant pressure, 
$c_{v}=$ specific heat of the gas at constant volume,

$P_{e}=$ absolute pressure of exhaust gas at nozzle exit, and

$P=$ absolute pressure of inlet gas ${ }^{13}$.

The variables $T$ and $P_{e}$ are the measured temperature and pressure inside the system chamber, by the sensors.

The "Configure Formula" function of LabVIEWTM (shown in Figure 6), allowed us to introduce the formulas to be implemented by introducing all the variables needed in the right order. In other words, the programmer transforms a formula into a mathematical statement that LabVIEW ${ }^{\text {TM }}$ can compute. When this statement is done, were able to connect the values for each variable expressed and the math once collected. Finally, the result was displayed at the right side of the function and may be connected to a graph simulator or to an indicator to read the number that has been computed.

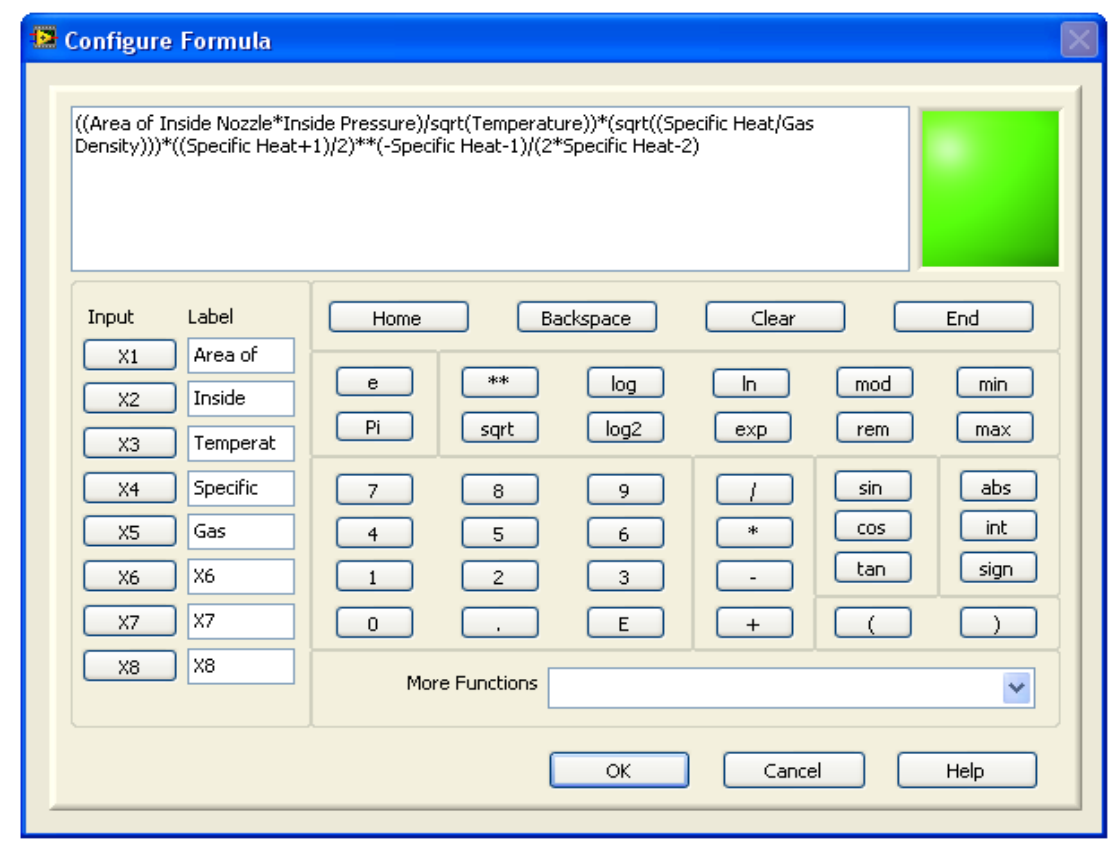

Figure 6. LabVIEW'M's Configure Formula Function

The exhaust velocity, formula 3, has been tested using a sample problem: "As an example calculation using the above equation, assume that the propellant combustion gases are: at an absolute pressure entering the nozzle of $P=7.0 \mathrm{MPa}$ and exit the rocket exhaust at an absolute pressure of $\mathrm{Pe}=0.1 \mathrm{MPa}$; at an absolute temperature of $\mathrm{T}=3500 \mathrm{~K}$; with an isentropic expansion factor of $k=1.22$ and a molar mass of $M=22 \mathrm{~kg} / \mathrm{kmol}$. Using those values in the above equation yields an exhaust velocity $V_{e}=2802 \mathrm{~m} / \mathrm{s}$ or $2.80 \mathrm{~km} / \mathrm{s}$ which is consistent with above typical values ${ }^{14}$."

First thing we did was to break the thrust formula in to its different components:

$$
\text { Thrust }=F=\dot{m} V_{e}+\left(p_{e}-p_{o}\right) A_{e}
$$


In the propulsion demonstrator's case, mass flow rate is defined as the amount of oxygen that is introduced to the chamber times the velocity times the cross sectional area that the oxygen is traveling.

Values:

$d=\frac{v}{m}$; the density of oxygen, $1.316 \mathrm{~kg} / \mathrm{m}^{3}$, was provided by the sponsor.

$V=\frac{n R T}{P}=24.13 \frac{\mathrm{m}}{\mathrm{s}^{2}}$; by using the ideal gas law, the velocity of oxygen coming out of the gas tank was figured out.

$A=0.03989832 \mathrm{~m}$; the cross sectional area was taken from the dimension of the pipe that lets the oxygen out of the gas tank.

Formula breakdown as follows: $V_{e}=\sqrt{\frac{T R}{M} * \frac{2 k}{k-1} *\left[1-\left(P_{e} / P\right)^{(k-1) / k}\right]}$

$T=600$ to $700 o_{C}$; estimate of flame burning ${ }^{15}$.

$M=159.6882 \frac{\mathrm{g}}{\mathrm{mol}} \mathrm{Fe}_{2} \mathrm{O}_{3}$; the reaction that spawns when metal wool and oxygen burn together is called Ferric Oxide.

$k=\frac{n-m o l * 3 R}{M}=0.78$; the specific heat capacity formula that was used to find $k$.

$P=50 \mathrm{psi}$; this is the amount needed by the propulsion demonstrator configuration in order to turn on.

$P_{e}=10-15 \mathrm{psi}$; this pressure was taken from approximation by using the word problem above.

The last part of the thrust formula deals with the absolute pressure of the exhaust gas, which is taken from the previous equation minus the atmospheric pressure times the cross sectional area of pipe where the flame will propagate: $\left(p_{e}-p_{o}\right) A_{e} . A=0.03989832 \mathrm{~m}$; the cross sectional area from the dimension of the nozzle of the rocket, as previously mentioned.

When this exhaust velocity problem was tested with the simulation interface, the result obtained was equal to the one mentioned in the problem: $V_{e}=2802 \mathrm{~m} / \mathrm{s}$. While this part of the calculations is regarded as accurate, the remaining thrust formula, $\dot{m} V_{e}+\left(p_{e}-p_{o}\right) A_{e}$, is still pending of simulation/testing. A sample problem, similar to the one used for exhaust velocity, could not be found.

Interface Operation:

Steps to test the program through the simulation interface are as follows: 
1. Have an approximated minimum and maximum value for the parameters ready to input such as:
a. Mass Flow Rate in $\frac{\mathrm{kg}}{\mathrm{s}}$
b. Temperature Out in $K$
c. Pressure Entering in Psi
d. Pressure Out in Psi
e. Cross-Sectional Area of nozzle in $\mathrm{m}^{2}$

2. Introduce those values where prompted.

3. Press Start Button.

4. Press Stop Button.

After pressing the Start button the values will be used calculate the parameters displayed at the bottom such as mass flow rate, exhaust velocity and finally, thrust.

Each second a new answer is calculated for each parameter, and the results graphed in the black space next to each of the prompt boxes. Each graph has a time graph time span of 10 seconds.

Steps for running the system's user interface controller are:

1. Get the upgraded propulsion demonstrator ready for "launch."

2. Press "Run" button or "Ctrl $+\mathrm{R}$ " to run coding.

3. For best results, introduce 7 Volts in "Flow Meter Controller" by moving the nudge or by putting it manually.

4. Press "Start" button

5. For turning off the system, press "Valve OFF" button to cut the oxygen from reaching the model, and thus, stopping the fire.

(If the green button next to it flashes after pressing the button, it means that the valve is completely off).

6. Finally press "Stop" button to cut the communication with sensors.

\section{System Integration:}

After integrating the software with the hardware components - ignition circuit, temperature and pressure sensors, mass flow meter, and DAQ - several successful firing demonstrations were performed. The results obtained were satisfactory, with opportunity for further enhancements.

\section{Conclusion and Recommendations}

This paper presented improvements to a propulsion demonstrator that was originally developed at NASA's Stennis Space Center. The new system reduces the manual work to operate, is user friendly, and provides important data. The device is controlled via a graphic user interface and collects and displays temperature and pressure measurements which are used for thrust computation. Recommendations for further improvement include verifying the thrust calculations and adding calibration procedures for the system components. The effects of placing the pressure sensor a few inches above the chamber on the pressure measurements need to be studied along with the calculated thrust. This research and educational project has given our students a great experience it is our hope that the final product will positively influence the recruitment and retention of young minds into the STEM fields. 


\section{Acknowledgments}

This project was partially supported by a grant from the National Space Grant Foundation. Work continues on this project with partial support by a grant from the Department of Education, award \# P120A110067. A group of six systems engineering students at TAMIU (Sofía Maldonado-Team Leader, Pablo Cisneros, Ralph Lopez, Fernanda Uribe, Alejandro Ramirez, and Gerardo Enriquez) worked on this project in Fall 2011. Another group of three systems engineering students at TAMIU (Enrique Villarreal-Team Leader, Andres Ortegon, and Eduardo Vasquez) is continuing work on this project in Fall 2012. Special thanks to Mr. Phillip Hebert and Mr. Bryon Maynard of Stennis Space Center for providing details about the original system and advising students throughout the development process. The support of Professors Juan Hinojosa and Rohitha Goonatilake is also acknowledged and appreciated.

\section{Bibliography}

1 "Increasing the Number of STEM Graduates: Insights from the U.S. STEM Education \& Modeling Project." Business-Higher Education Forum, 2010. Web. 4 Jun 2012.

<http://www.bhef.com/solutions/documents/BHEF_STEM_Report.pdf>.

2 "Improving Science, Technology, Engineering, and Mathematics (STEM) Education." U.S. Department of Education, 14 Feb 2011. Web. 4 Jun 2012.

<http://www2.ed.gov/about/overview/budget/budget12/crosscuttingissues/stemed.pdf〉.

${ }^{3}$ Eberle, Francis. "Why STEM education is important | ISA." InTech. ISA, 2010. Web. 22 May 2012.

<http://www.isa.org/InTechTemplate.cfm?template=/ContentManagement/ContentDisplay.cfm\&ContentID=83593

$>$.

4 "LM741 Operational Amplifier Data Sheet." Texas Instruments, Aug 2000. Web. 19 Jun 2012. <http://www.ti.com/lit/ds/symlink/lm741.pdf>.

5 "Industrial RTD Probes for Air, Gas and Liquid Measurement." Omega. N.p., 2012. Web. 22 May 2012. <http://www.omega.com/ppt/pptsc.asp?ref=RTD-870_RTD-880>.

${ }^{6}$ RTD Temperature vs. Resistance Table. Omega, n.d. Web. 22 May 2012.

<http://www.omega.com/temperature/z/pdf/z252-254.pdf $>$.

7 "Rugged Pipe Plug Thermocouple Probe with 1/4 NPT or 1/8 NPT Fitting." Omega. N.p., 2012. Web. 22 May 2012. <http://www.omega.com/pptst/TC-NPT.html>.

8 "Solid State Pressure Transducer, 0 to 5 Vdc or 4 to 20 mA Outputs, Vacuum to 300 psi Ranges." Omega.com. N.p., 2012. Web. 23 Oct 2012. <http://www.omega.com/pptst/PX209_PX219.html>.

9 "Installation and operation manual." Mass flow controller. N.p., n.d. Web. October, 2008. <http://www.brooksinstrument.com/downloads/Product Documentation/Thermal Mass Flow Meters Controllers Analog Gas/Instruction Manuals/x-tmf-5850e-mfc-eng.pdf>.

10 "NI USB-6211 - 16-Bit, 250 kS/s M Series Multifunction DAQ, Bus-Powered - National Instruments." National Instruments. N.p., 2012. Web. 22 May 2012. <http://sine.ni.com/nips/cds/view/p/lang/en/nid/203224>. 
11 "Rocket Thrust Equation." NASA. N.p., n.d. Web. 22 May 2012. <http://exploration.grc.nasa.gov/education/rocket/rockth.html>.

12 "Mass Flow Rate." NASA. N.p., n.d. Web. 22 May 2012. <http://www.grc.nasa.gov/WWW/k12/airplane/mflow.html>.

${ }^{13}$ Nakka, Richard. Richard Nakka's Experimental Rocketry Site. N.p., 15 Dec 2006. Web. 22 May 2012. <http://www.nakka-rocketry.net/th_nozz.html>.

${ }^{14}$ Rocketry, an Introduction. Wikimedia Foundation, 14 Nov 2010. Web. 22 May 2012. <http://books.google.com/books?id=U2lyDeRpo5EC\&lpg=PA84\&ots=fP0vNQgdcL\&dq> .

15 "Flame Temperatures some Common Gases." The Engineering ToolBox. N.p., n.d. Web. 22 May 2012. $<$ http://www.engineeringtoolbox.com/flame-temperatures-gases-d_422.html>. 